\title{
Flow microenvironment of two marine peritrich ciliates with ectobiotic chemoautotrophic bacteria
}

\author{
Kay Vopel ${ }^{1, *}$, Christian H. Reick ${ }^{1}$, Günter Arlt ${ }^{2}$, Martina Pöhn ${ }^{3}$, Jörg A. Ott ${ }^{3}$ \\ ${ }^{1}$ Alfred Wegener Institute for Polar and Marine Research, Columbusstr. , 27568 Bremerhaven, Germany \\ ${ }^{2}$ Institute for Aquatic Ecology, Marine Biology, University of Rostock, Freiligrathstr. 7/8, 18051 Rostock, Germany \\ ${ }^{3}$ Department of Marine Biology, Institute of Ecology and Conservation Biology, University of Vienna, Althanstr. 14, \\ 1090 Vienna, Austria
}

\begin{abstract}
The flow microenvironment of 2 marine peritrich ciliates, Vorticella sp. and Zoothamnium niveum, with ectobiotic sulfur bacteria was studied with frame-by-frame analyses of video sequences and a microsensor for fluid velocity. Both species populate the chemocline above $\mathrm{H}_{2} \mathrm{~S}-$ releasing mangrove peat. Vorticella sp. moves the surrounding seawater up to a horizontal and vertical distance of at least $400 \mu \mathrm{m}$ with a maximum flow velocity of $18 \mathrm{~mm} \mathrm{~s}^{-1}$ close to its peristomial edge. The feather-shaped colonies of $Z$. niveum generate a unidirectional flow of seawater passing the colony perpendicular to the stalk; the convex side of the feather faces upstream. The flow velocity increased exponentially towards the colony, up to $11 \mathrm{~mm} \mathrm{~s}^{-1}$ at a distance of $100 \mu \mathrm{m}$. Contraction of the stalk forces the zooids of Vorticella sp. and Z. niveum towards the substrate at a high velocity of 71 and $520 \mathrm{~mm} \mathrm{~s}^{-1}$, respectively. During contraction of Vorticella sp., only little seawater is dragged along towards the surface to which the ciliates are attached whereas the contraction of $Z$. niveum resulted in a clear increase in the velocity of the seawater both surrounding the colony and above the substrate. Extension of the species proceeds 700 to 1000 times more slowly than contraction, and the surrounding seawater sticks to the cells and therefore is dragged along. The measurements given here support our earlier data indicating the importance of the feeding current for the bacteria-ciliate association, i.e. the cilia beat drives $\mathrm{H}_{2} \mathrm{~S}$ - and $\mathrm{O}_{2}$-containing seawater toward the zooid at high velocity and thus, supports the growth of the ectobiotic sulfide-oxidizing bacteria. Rapid movement, shrinkage (Vorticella sp.) and bunching ( $Z$. niveum) of the zooids during stalk contraction apparently cause sufficient shear stress to abrade ectobiotic bacteria that, once suspended, could enter the feeding currents.
\end{abstract}

KEY WORDS: Sulfur ectosymbioses - Chemoautotrophic bacteria Peritrich ciliates $\cdot$ Vorticella Zoothamnium niveum $\cdot$ Flow velocity

\section{INTRODUCTION}

Bacterivorous ciliates exploit spatially and temporally patchy sources of high concentrations of food, such as early successional stages of easily degradable organic material (Fenchel 1980, Fenchel \& Blackburn 1999). This behavior implies adaptations for a fugitive life:

${ }^{*}$ Present address: Department of Oceanography, Florida State University, Tallahassee, Florida 32306-4320, USA. E-mail: cvopel@ocean.fsu.edu high mobility, short generation times, the ability to ingest large volumes of food within short periods as well as the ability to encyst when food is exhausted. This characterization also apparently applies to the peritrich ciliates Vorticella (Linnaeus, 1767) and Zoothamnium Bory de Saint Vincent, 1826, in which only the swarmer stages possess mobility. The species Zoothamnium niveum (Hemprich \& Ehrenberg, 1831) and an undescribed species of Vorticella (Vorticella sp.) aggregate on decomposing debris or on vertical rocks adjacent to debris in Mediterranean Posidonia meadows 
(west coast of Corsica, France) and around decaying rootlets at the surface of vertical walls of mangrove peat (Belize, Tobacco Reef section). Here, degradation of organic material leads to a production of $\mathrm{H}_{2} \mathrm{~S}$ that is mixed with the surrounding $\mathrm{O}_{2}$-saturated seawater by hydrodynamic forces. These conditions support associations between the ciliates and colorless sulfur bacteria. SEM micrographs showed that in $Z$. niveum all but the most basal parts of the specimens are covered with an irregular layer of coccoid and rod-shaped bacteria (Bauer-Nebelsick et al. 1996a,b). The white appearance of the bacteria is caused by cellular inclusion of elemental sulfur and makes the bacteria-ciliate association conspicuous. From characteristic and specific ultrastructural affinities between $Z$. niveum and the ectobiotic bacteria, Bauer-Nebelsick et al. (1996b) inferred a symbiotic relationship. There is evidence that the ciliates feed on their chemoautotrophic ectobionts because food vacuoles contain only bacteria with the same characteristic ultrastructure as the symbionts (Bauer-Nebelsick et al. 1996a). In addition, the higher growth rates in colonies with ectobionts compared to those of aposymbiotic colonies suggest a trophic relationship. Nevertheless, the detailed nature of the ciliate-bacteria association is not fully understood.

The species Vorticella sp. and Zoothamnium niveum are composed of zooids and long contractile stalks. The stalks elevate the zooids whose peristomial cilia transport seawater, which is filtered for suspended particles. Feeding is repeatedly interrupted by rapid contractions involving cell-body shrinkage and coiling of the stalk. Thereafter, the stalk slowly uncoils, the cell extends and the cilia restart beating (HoffmannBerling 1958, Amos et al. 1976, Katoh \& Naitoh 1994). Ott et al. (1998) used the ciliate's capability of contraction to explain how the ectobiotic bacteria are supplied with $\mathrm{O}_{2}$ and $\mathrm{H}_{2} \mathrm{~S}$. They assumed that the zooids alternately bathed in $\mathrm{H}_{2} \mathrm{~S}$-free, fully oxygenated seawater (in upright position) and in deoxygenated, $\mathrm{H}_{2} \mathrm{~S}$-containing seawater (when contracted), exploiting sharp gradients above a $\mathrm{H}_{2} \mathrm{~S}$-releasing substrate. It was argued that rapid contraction of the ciliates increased the Reynolds number and prevented $\mathrm{O}_{2}$-laden seawater from being dragged along, which otherwise would push the sulphidic bottom water away before contact with the bacteria. Subsequently, this model was tested by applying fast-responding amperometric $\mathrm{O}_{2}$ and $\mathrm{H}_{2} \mathrm{~S}$ microelectrodes to bacteria-ciliate associations reared in the laboratory on $\mathrm{H}_{2} \mathrm{~S}$-releasing substrates (Vopel et al. 2001). These measurements indicated that it is not the bathing of the ectobiotic bacteria alternately in anoxic, $\mathrm{H}_{2} \mathrm{~S}$-containing and $\mathrm{O}_{2}$-saturated seawater, but the cilia-generated advective seawater transport that turns the zooids external surface into an attractive microhabitat for chemoautotrophic bacteria; it was suggested that, in both ciliate species, rapid stalk contraction and subsequent slow extension merely contributed to the mixing of oxygenated and deoxygenated $\mathrm{H}_{2} \mathrm{~S}$-containing seawater within the substrate-seawater boundary layer. These conclusions, however, were drawn from recordings of $\left[\mathrm{O}_{2}\right]$ and $\left[\mathrm{H}_{2} \mathrm{~S}\right]$ around the contracting ciliates and from the extent to which diffusional $\mathrm{O}_{2}$ - and $\mathrm{H}_{2} \mathrm{~S}$-gradients were modified by the cilia-generated current. Direct measurements of the seawater flow itself, which is responsible for the formation of a physico-chemical microenvironment that supports the bacteria-ciliate ectosymbioses, have so far not been carried out. Here, we present measurements of the seawater flow around Vorticella sp. and $Z$. niveum, and we discuss the results in the context of the functioning of the bacteria-ciliate associations.

\section{MATERIALS AND METHODS}

Sampling. Vorticella sp. and Zoothamnium niveum were collected from vertical, overhanging walls of sulphidic red mangrove (Rhizophora mangle Linnaeus) peat of the mangrove island Twin Cays in January 2001. Twin Cays is situated inside the Tobacco Reef section of the Belize barrier reef $\left(16^{\circ} 48^{\prime} \mathrm{N}, 088^{\circ} 05^{\prime} \mathrm{W}\right)$. The sampling site was located at the north end of the tidal channel (Batfish Point) that cuts the island in two. Detailed information about the site and a description of the area are available from Rützler \& Macintyre (1982) and Ott et al. (1998). The ciliates are easily detected at the surface of the peat walls because of their bright coating of sulfur bacteria. They occur in groups aggregated around decomposing rootlets. Two small pieces of peat with attached ciliate groups were cut off the peat wall on 4 successive days and transported $3.5 \mathrm{~km}$ seawards to the island Carrie Bow Cay, where the laboratory of the Caribbean Coral Reef Ecosystem program of the National Museum of Natural History (Washington, DC) is located. For microelectrode measurements and video recordings, the material was then transferred into small aquaria $(10 \times 10 \times 20 \mathrm{~cm})$ filled with seawater (temperature $26^{\circ} \mathrm{C}$, salinity 34 ). At least 2 individuals of Vorticella sp. and 3 colonies of $Z$. niveum were investigated no more than 2 to $4 \mathrm{~h}$ after the ciliates were collected on each of $4 \mathrm{~d}$.

Microscale flow-velocity measurements. The flow velocity of the seawater surrounding the ciliates was recorded with a flow microsensor (FS20, closed reservoir type, Unisense A/S) based on a miniaturized amperometric microtransducer, surrounded by a $\mathrm{H}_{2}$ reservoir that was closed by a tip membrane. The gas transducer was mounted with its detecting tip within the membrane. The diffusive loss of $\mathrm{H}_{2}$ through the 
membrane resulted in a decrease in its partial pressure across the membrane and throughout the diffusion sphere in the surrounding seawater. In still water, only a small partial-pressure gradient developed, causing a high amperometric reading. In flowing water, the diffusion sphere was eroded and the $\mathrm{H}_{2}$ partial pressure decreased at the sensing tip, resulting in a low signal. The sensor tip had an outer diameter of $50 \mu \mathrm{m}$ and a response time of $<1 \mathrm{~s}$ for increasing fluid velocity. Response time was longer for decreases in fluid velocity.

Calibration of the flow-velocity microsensor was carried out at the experimental temperature of $26^{\circ} \mathrm{C}$ by mounting the sensor vertically with the tip immersed in a seawater-filled circular channel. The channel was made of 2 plastic Petri-dishes ( 6 and $9 \mathrm{~cm}$ in diameter) with the smaller one placed inside the larger. The circular flow channel was mounted on the roller-head of an ISMATEC peristaltic pump (Ismatec Laboratoriumstechnik) and rotated at a frequency of 0 to $41.4 \mathrm{rpm}$, creating fluid velocities of 0 to $174 \mathrm{~mm} \mathrm{~s}^{-1}$. The sensor had its highest sensitivity at low fluid velocities between 0 and $50 \mathrm{~mm} \mathrm{~s}^{-1}$, but remained sensitive up to $150 \mathrm{~mm} \mathrm{~s}^{-1}$.

For recordings of fluid-velocity profiles, the sensor was mounted on a micromanipulator (Märzhäuser) driven by stepping motors, secured to a stable iron frame and moved vertically at $50 \mu \mathrm{m}$ increments with a remote control. A dissection microscope (Olympus, SZ60) mounted on a tripod was used for positioning the sensor tip. Continuous measurements of flow velocity during animal contraction were carried out with the sensor positioned at an angle of $90^{\circ}$ relative to the stalk of the ciliates. The sensor current, measured by a picoampere meter (PA2000, Unisense), was continuously logged with a frequency of $50 \mathrm{~Hz}$, amplified to $\mathrm{mV}$ and digitized by an analogue-to-digital converter (DI 220, Dataq Instruments) for PC data acquisition.

Analysis of video images. Contraction and extension of the ciliates was studied with frame-by-frame analysis of video-image sequences (at 29.97 frames $\mathrm{s}^{-1}$ ) taken by means of a digital camera mounted on an Olympus microscope. Visualization of the flow field around Zoothamnium niveum was carried out by adding amyl maize particles to the seawater. For length measurements, the image-analyzing software AnalySIS Pro (Soft Imaging System) was used.

Calculations. To estimate the duration of extension, we divided the average number of video images it took the ciliate to extend the stalk $(m)$ by the number of frames per second $(f)$. The average duration of extension $t_{\mathrm{r}}$ is obtained from: $t_{\mathrm{r}}=m f^{-1}$.

Determining the contraction time is somewhat more complicated. The video camera was equipped with a shutter, so that during recording sessions, periods dur- ing which the aperture was closed alternated with periods when it was open. The duration of the latter will be called exposure time in the following analysis. Frame-by-frame inspection of the video images revealed that a full contraction is visible in a single frame (i.e. the ciliate appears in both the fully upright and the contracted position). Accordingly, the contraction time must be shorter than the exposure time. Because of this circumstance, it is possible to estimate the contraction time, without knowledge of the exposure time, only on the basis that exposure time does not change (light intensity did not change during takes) and that the contraction time is nearly constant. Let $N$ denote the number of analyzed contractions and $n$ the number of video images where only part of the contraction is seen, i.e. where either the beginning or the end of the contraction falls into the exposure. Let $T=$ $f^{-1}$ denote the duration of 1 frame, i.e. the sum of closed aperture time plus exposure time. Then, the probability of finding the beginning but not the end of a contraction within the exposure time is $\tau_{\mathrm{c}} T^{-1}$, where $\tau_{c}$ denotes the average contraction time (this formula holds only because $\tau_{\mathrm{c}}<T$ ). The probability of finding the end of the contraction but not the beginning inside the exposure time is also $\tau_{\mathrm{c}} T^{-1}$. Accordingly, the probability of finding images showing only part of the contraction is $2 \tau_{\mathrm{c}} T^{-1}$. For a sufficiently large number of analyzed contractions, the abundance $n N^{-1}$ should thus converge to this probability so that: $\tau_{\mathrm{c}} \sim n T(2 N)^{-1}$ $=n(2 N f)^{-1}$, estimates the contraction time.

The Reynolds number, Re, was calculated according to: $\operatorname{Re}=V r v^{-1}$, where $V$ is the velocity, $r$ is the radius of the cell (Vorticella sp.) or the width of the colony (Zoothamnium niveum) and $v$ is the kinematic viscosity of the seawater $\left(\sim 9.14 \times 10^{-7} \mathrm{~m}^{2} \mathrm{~s}^{-1}\right.$ at $\left.26^{\circ} \mathrm{C}\right)$. The drag of a sphere at low Reynolds numbers $(D)$ was calculated according to Stokes' law: $D=6 \pi \eta r V$, where $\eta$ is the dynamic viscosity $\left(\sim 0.93 \mathrm{~g} \mathrm{~m}^{-1} \mathrm{~s}^{-1}\right.$ at $\left.26^{\circ} \mathrm{C}\right)$.

\section{RESULTS}

\section{Flow regime around Vorticella sp. and Zoothamnium niveum}

Successive measurements of the seawater velocity around a single, upright, $400 \mu \mathrm{m}$ tall Vorticella sp. revealed steep horizontal and vertical gradients (Fig. 1, note the logarithmic scale). The vertical and horizontal profiles were recorded in $50 \mu \mathrm{m}$ increments over a distance of $400 \mu \mathrm{m}$ either parallel or perpendicular to the stalk, starting with the sensor tip at a horizontal distance of $50 \mu \mathrm{m}$ from the peristomial edge of the ciliate. At this position, the fluid velocity was $\sim 18 \mathrm{~mm} \mathrm{~s}^{-1}$. The values decreased with increasing 

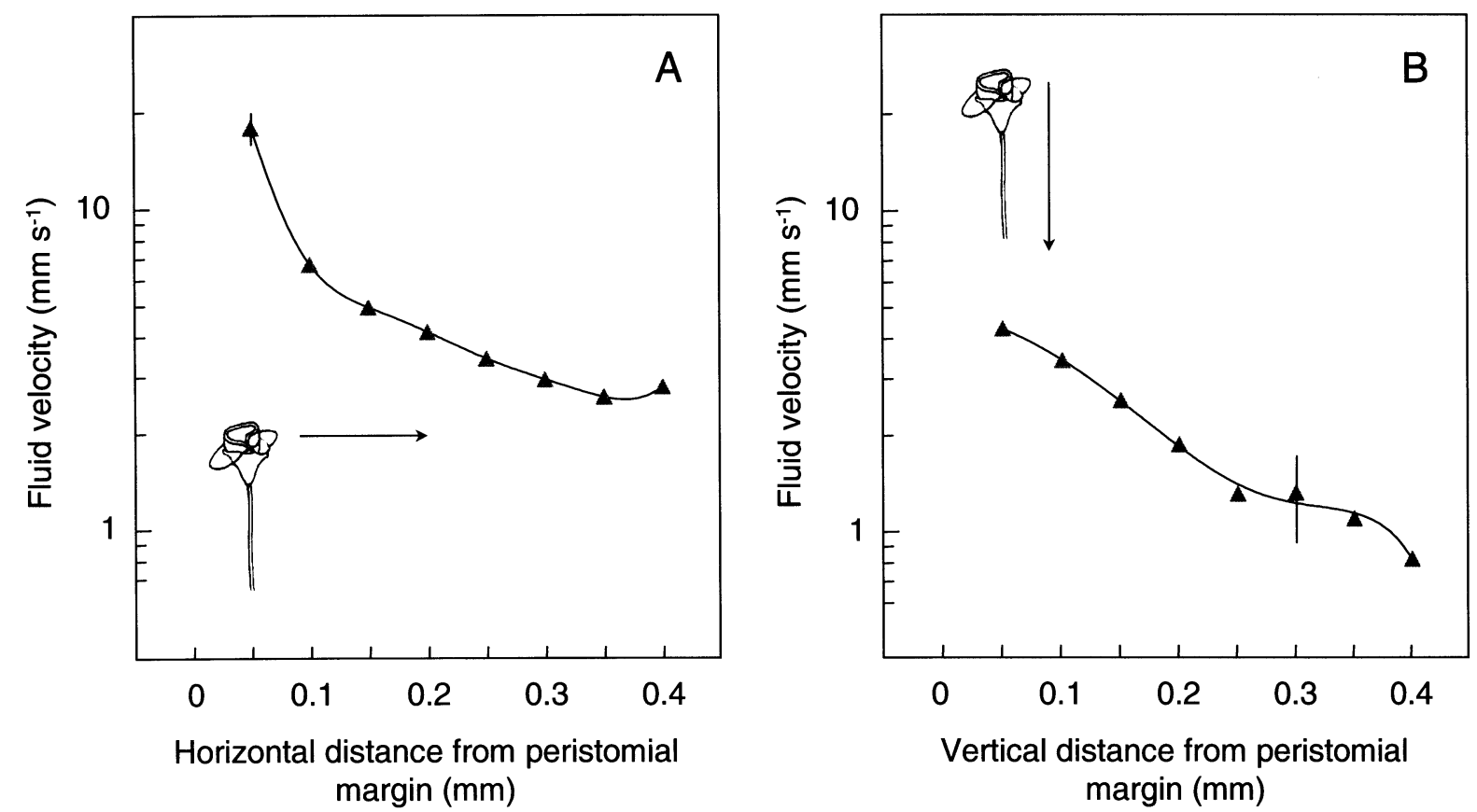

Fig. 1. Vorticella sp. Horizontal (A) and vertical (B) fluid-velocity profiles around a solitary $400 \mu \mathrm{m}$ tall specimen. The vertical profile was recorded with a horizontal distance of the flow sensor tip from the outer margin of the peristome of $50 \mu \mathrm{m}$. Means of 1000 data points recorded at $50 \mathrm{~Hz}$ within $20 \mathrm{~s}(\mathbf{\Lambda})$. All measurements were carried out successively with the sensor orientated perpendicular to the stalk. Note that the ordinate is log-scaled

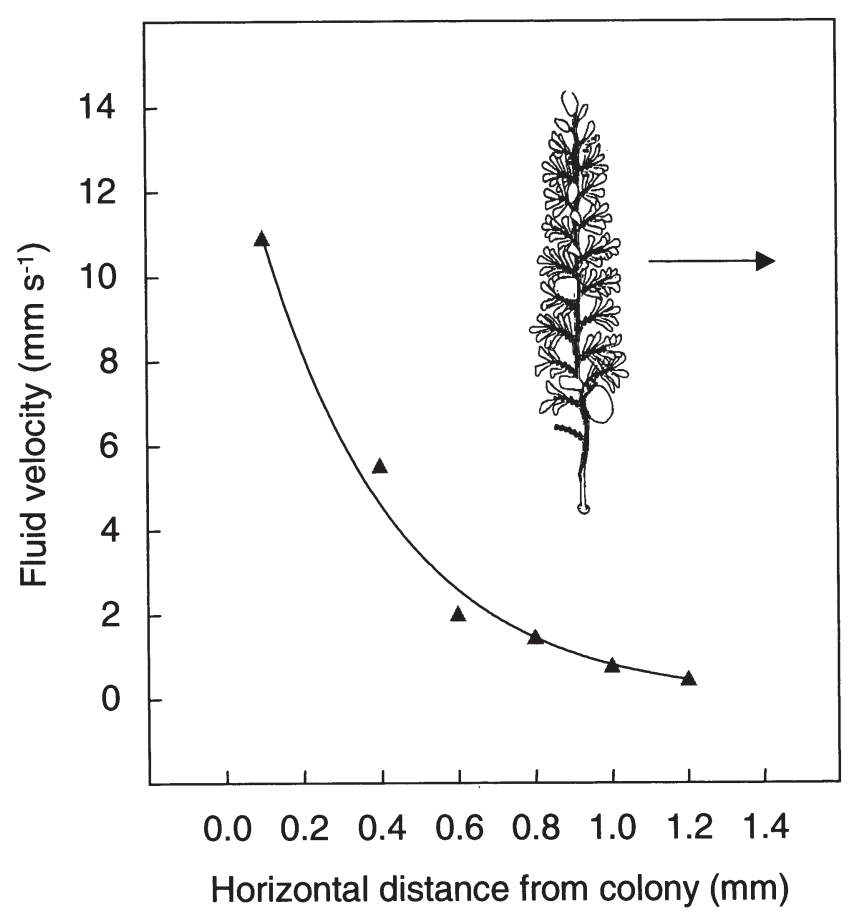

Fig. 2. Zoothamnium niveum. Horizontal fluid-velocity profile around a $1.8 \mathrm{~mm}$ tall colony, exponential fitting. Measurements were carried out successively with increasing distance of the flow-sensor tip from the colony distance of the sensor tip from the cell in horizontal and vertical direction. Lowest velocities of 2.6 and $0.8 \mathrm{~mm} \mathrm{~s}^{-1}$ were recorded at a horizontal distance of $350 \mu \mathrm{m}$ (Fig. 1A) and at the base (Fig. 1B) of the ciliate, respectively.

Frame-by-frame analyses of video sequences showed that the branched colonies of Zoothamnium niveum generated a unidirectional flow of seawater, perpendicular to the longitudinal axis of the stalk with the convex side of the feather facing upstream. Small particles accelerated toward the peristome and were caught in peripheral whirls. The velocity of the surrounding seawater increased exponentially with decreasing horizontal distance from the colony (Fig. 2). Measurements with the sensor tip $100 \mu \mathrm{m}$ away from $1.8 \mathrm{~mm}$ tall colonies detected a fluid velocity of $\sim 11 \mathrm{~mm}$ $\mathrm{s}^{-1}$ which decreased to $0.5 \mathrm{~mm} \mathrm{~s}^{-1}$ at a horizontal distance of $1.2 \mathrm{~mm}$. We were not able to measure the seawater velocity at a distance smaller than 50 (Vorticella sp.) or $100 \mu \mathrm{m}$ ( $Z$. niveum) because at these distances the horizontal position of the ciliates was changed due to the deformation of the flow field by the presence of the sensor tip. Measurements with the sensor tip in contact with the zooids gave extremely low signals that would correspond to very high fluid velocities. These readings, however, are inaccurate because the diffusive boundary layer above the membrane of the sensor 
Table. 1. Vorticella sp. and Zoothamnium niveum. Size of specimens in upright and contracted position, duration and velocity of contraction and extension, and quotient of the respective Reynolds numbers for contraction $\left(\operatorname{Re}_{c}\right)$ and extension $\left(\operatorname{Re}_{\mathrm{E}}\right)$

\begin{tabular}{|c|c|c|c|c|c|c|c|}
\hline \multirow[t]{2}{*}{ Species } & \multicolumn{2}{|c|}{ Size (mm) } & \multicolumn{2}{|c|}{ Duration (s) } & \multicolumn{2}{|c|}{ Velocity $\left(\mathrm{m} \mathrm{s}^{-1}\right)$} & \multirow[t]{2}{*}{$\operatorname{Re}_{\mathrm{C}} / \operatorname{Re}_{\mathrm{E}}$} \\
\hline & Upright & Contracted & Contracted & Extended & Contracted & Extended & \\
\hline Vorticella sp. & 0.47 & 0.16 & $4.4 \times 10^{-3}$ & 6.7 & 0.07 & $0.5 \times 10^{-4}$ & 730 \\
\hline Z. niveum & 1.4 & 0.45 & $2.6 \times 10^{-3}$ & 1.4 & 0.37 & $6.8 \times 10^{-4}$ & 1039 \\
\hline Z. niveum & 2.9 & 0.70 & $4.2 \times 10^{-3}$ & 4.2 & 0.52 & $5.2 \times 10^{-4}$ & 1000 \\
\hline
\end{tabular}

was physically destroyed (removed) by the beat of the paroral ciliature.

\section{Ciliate contraction and extension}

Analyses of video sequences of 19 contractions revealed that Vorticella sp. contracts within $4.4 \mathrm{~ms}$; the median velocity of the zooid during a contraction was $71 \mathrm{~mm} \mathrm{~s}^{-1}$ (Table 1). Contraction reduced the height of the zooid above the substrate to $34 \%$ of its height in the fully upright position. The average maximum width of the bell-shaped zooid (including the peristomial cilia) was $149.8 \pm 1.9 \mu \mathrm{m}$ in the state of full extension (Fig. 3). Cell shrinkage during contraction reduced the width of the zooid to $77.5 \pm 5.9 \mu \mathrm{m}(52 \%)$. When the zooid was retracted, the whole peristome with the peristomial disc, oral lip and most parts of the lobe were withdrawn, giving the zooid a globular shape. Immediately after this rapid contraction, the slower extension began, accompanied by a counterclockwise rotation of the zooid. The extension of the cell body and the stalk lasted $\sim 6.7 \mathrm{~s}$, reaching a maximum extension speed of $9.7 \times 10^{-2} \mathrm{~mm} \mathrm{~s}^{-1}, 2$ to $3 \mathrm{~s}$ after completion of contraction (calculated from the slope of the curve in Fig. 3). The zooid traveled a distance of $\sim 310 \mu \mathrm{m}$ at an average speed of $4.7 \times 10^{-2} \mathrm{~mm} \mathrm{~s}^{-1}$ (Table 1). Given the mean velocity for contraction and extension, the calculated Reynolds numbers are 2.7 and $3.7 \times 10^{-3}$, respectively.

Contraction and extension of Zoothamnium niveum differed from Vorticella sp. in the way the stalk folded and unfolded as well as in the velocity of the movements. In $Z$. niveum, the stalk, whose proximal part lacks a spasmoneme, bent at a definitive joint, while the remainder coiled in a zigzag course. As a result, the bunched mass of zooids whipped downwards. The zooids of smaller colonies did not contact the surface during contraction, but in larger colonies, the distal part of the bunched mass of zooids struck against the surface (Fig. 4A-1). Thereafter, the proximal, contractile end of the stalk extended, deviating from the vertical axis with the fixed joint at the distal end of the noncontractile stalk on one side and the bunch of zooids on the other (Fig. 4A-2). Accordingly, the mass of zooids was lifted and the distal end of the bunch was pulled up to the stalk. Finally, the contracted feather stretched vertically, with the tip following a wide, semicircular path until reaching the upright position (Fig. 4A-3). The maximum, horizontal dimension of a $2.9 \mathrm{~mm}$ tall feather increased and decreased twice during the process of contraction and extension: $0.40 \mathrm{~mm}$ in the fully upright position, $0.72 \mathrm{~mm}$ when contracted (down at the surface), $0.53 \mathrm{~mm}$ after the lower part of the contractile stalk had been extended and $1.04 \mathrm{~mm}$ during extension of the remaining, branched part of the colony.

The time to complete contraction and the subsequent extension of Zoothamnium niveum increased with increasing size of the colony (or number of ramifications, Fig. 4B). The smallest colony we analyzed was $1.4 \mathrm{~mm}$ tall (10 branches) and completed its contraction within only $2.6 \mathrm{~ms}$, whereas the largest colony $(2.9 \mathrm{~mm}$ tall, 33 branches) contracted within $4.2 \mathrm{~ms}$ (Table 1). The extension of the small and the large colony lasted 1.4 and $4.2 \mathrm{~s}$, respectively. During a contraction/exten-

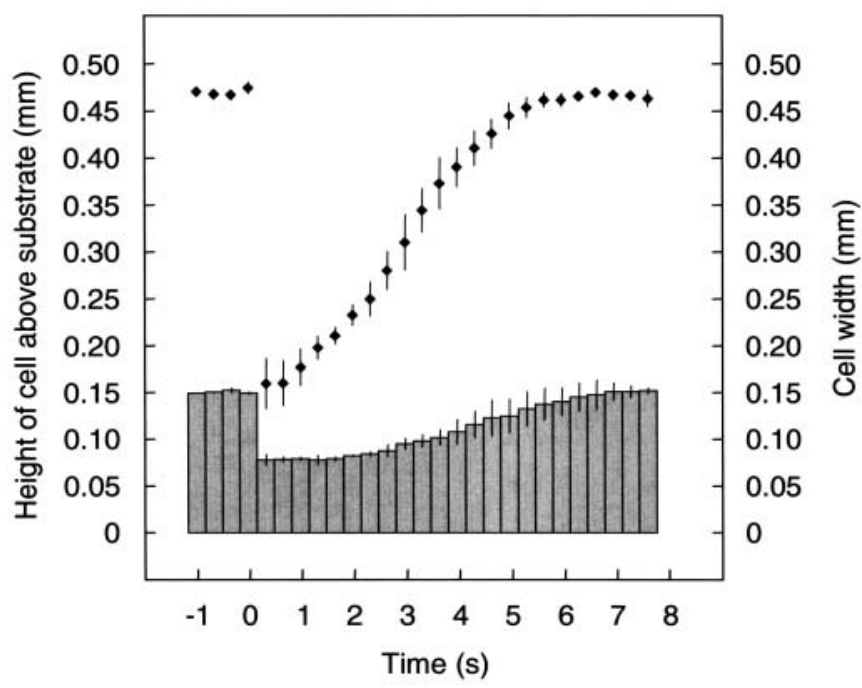

Fig. 3. Vorticella sp. Time course of changes in cell width, including peristome (bars) and height above the substrate (symbols) during the contraction/extension cycle (means \pm $\mathrm{SD}, \mathrm{n}=4)$ 

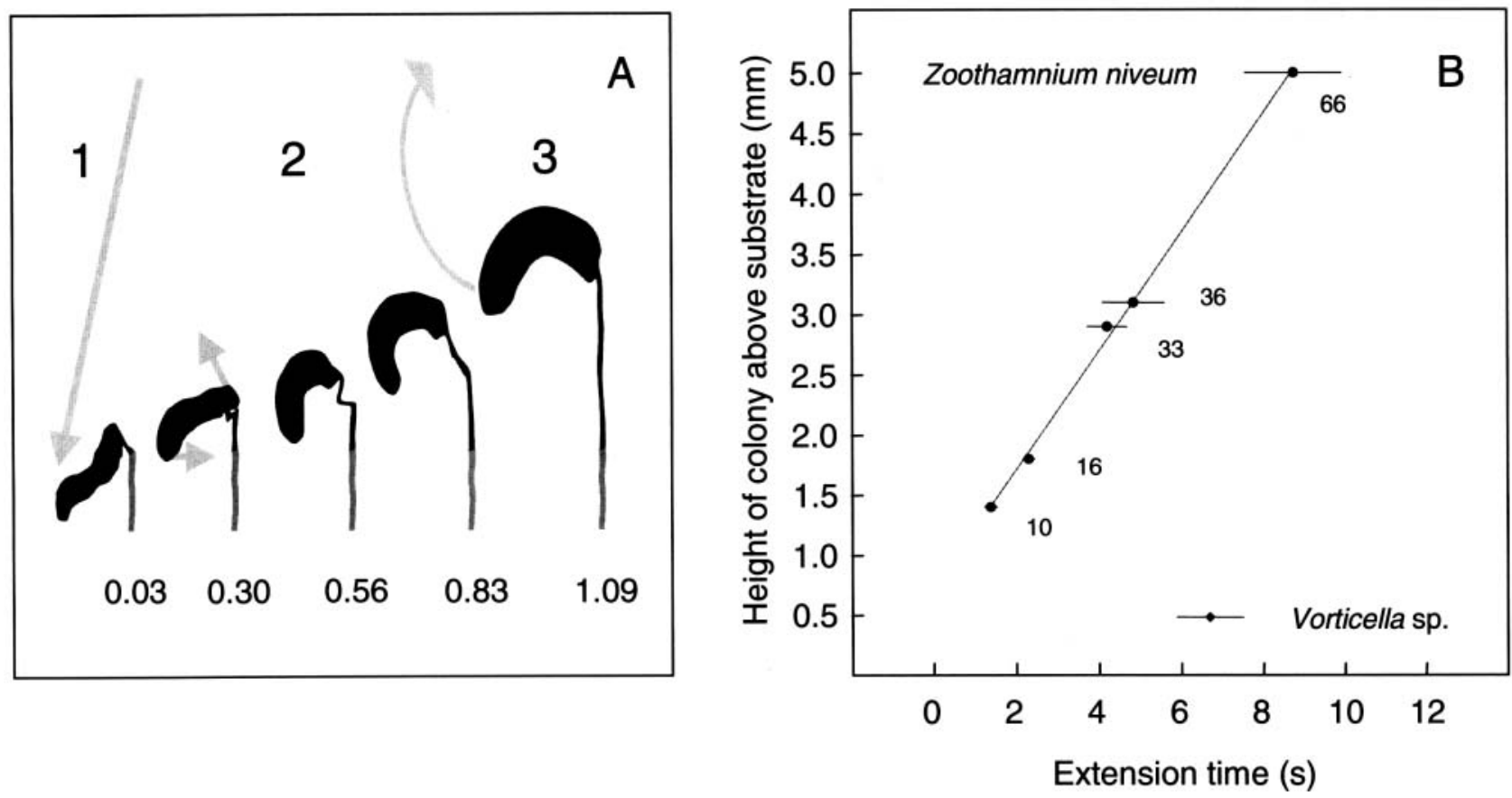

Fig. 4. Vorticella sp. and Zoothamnium niveum. (A) Schematic drawing of an extending, $2.9 \mathrm{~mm}$ tall colony of $Z$. niveum. Numbers below the drawing indicate time in seconds after onset of contraction (1) and initial phase of extension (2-3). Arrows indicate the direction of movement. (B) Extension time (means \pm SD) of different-sized colonies of Z. niveum $(n=6)$ and Vorticella sp. $(\mathrm{n}=4)$. Numbers indicate the number of branches per colony
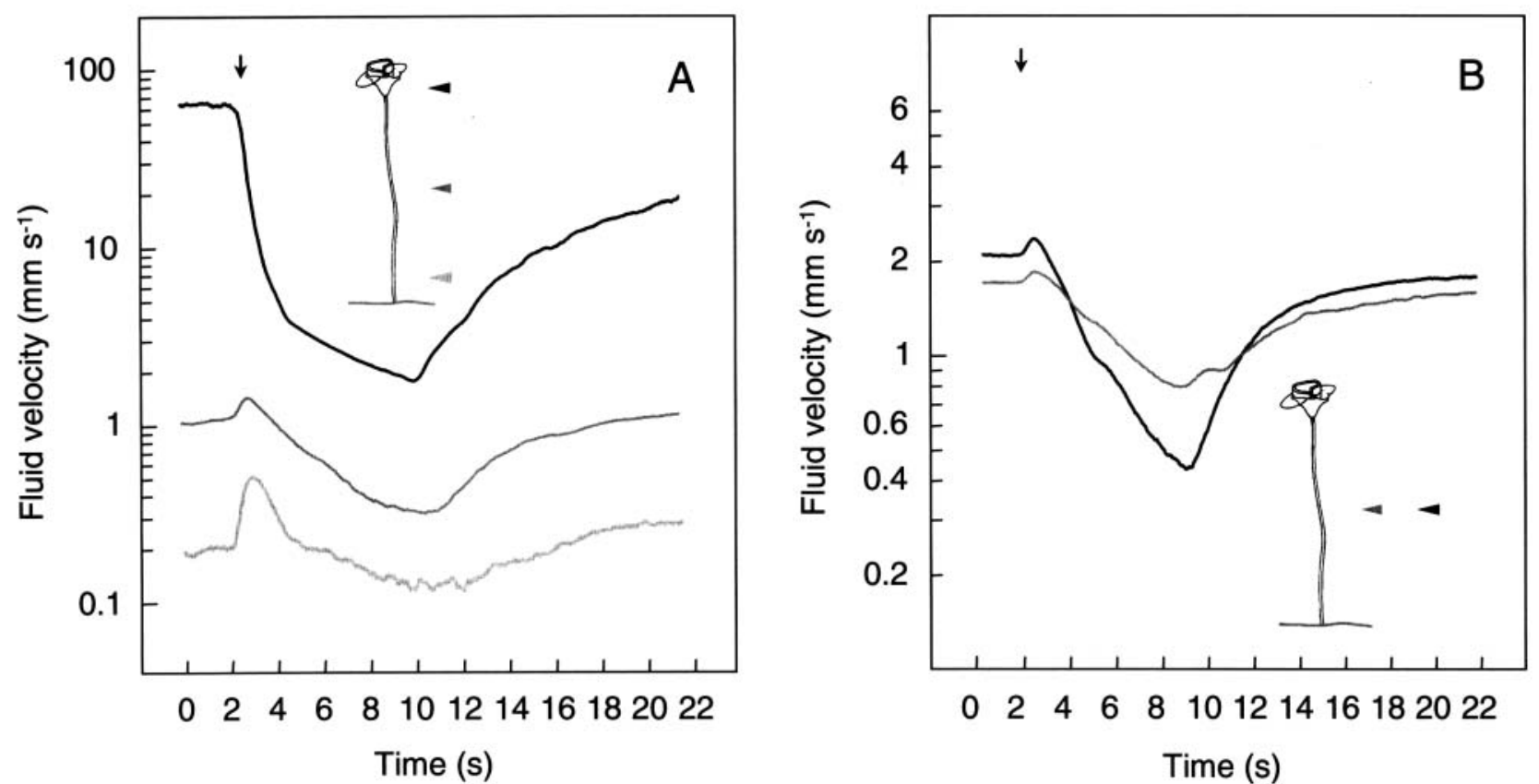

Fig. 5. Vorticella sp. Fluid velocity around a solitary contracting and subsequently expanding specimen measured (A) with a vertical distance of the sensor tip of 50 (light gray), 200 (gray) and $400 \mu \mathrm{m}$ (black) from the substrate, and (B) with a vertical distance of the sensor tip from the substrate of $200 \mu \mathrm{m}$ and a horizontal distance from the stalk of 50 (dark gray) and $150 \mu \mathrm{m}$ (black). All measurements were carried out successively with the sensor orientated perpendicular to the stalk. Vertical arrows indicate onset of contraction. Note log-scaled ordinates 
sion cycle, the height of the small colony was reduced by $0.95 \mathrm{~mm}$, resulting in a median velocity of the distal zooids of 370 and $68 \mathrm{~mm} \mathrm{~s}^{-1}$ for contraction and extension, respectively. The larger, 33 branch colony contracted with a higher velocity of $520 \mathrm{~mm} \mathrm{~s}^{-1}$; during extension, the distal zooids of the colony moved upwards with a mean velocity of $52 \mathrm{~mm} \mathrm{~s}^{-1}$. The Reynolds numbers for contraction and extension were 81 and $78 \times$ $10^{-3}$, respectively, for the 10 branch colony and 130 and $130 \times 10^{-3}$, respectively, for the 33 branch colony.

\section{Effects of ciliate contraction on seawater flow}

The seawater-velocity profiles reconstructed from successive recordings around filtering Vorticella sp. and Zoothamnium niveum reflect an instantaneous picture only. Both species exhibited contraction, involving graded shrinkage of the cell body and coiling of the stalk, that severely affected the flow of the surrounding seawater. Continuous recordings around a solitary contracting Vorticella sp., with a horizontal distance of the sensor tip from the stalk of $50 \mu \mathrm{m}$, revealed temporal variations in the seawater velocity (Fig. 5A): contraction resulted in a rapid decrease of the flow velocity $400 \mu \mathrm{m}$ above the substrate (height of the cell in fully upright position) within the first $2 \mathrm{~s}$, which continued less rapidly for another $6 \mathrm{~s}$, followed by a lengthier but continuous increase. Measurements carried out with the sensor tip positioned at half the zooid's height $(200 \mu \mathrm{m}$ above the substrate, Fig. 5A,B, dark gray arrows and curves) showed a different pattern, i.e. a brief increase of the flow velocity directly after the onset of contraction, followed by a lengthier decrease with an intermediate decrease in slope ('shoulder'). Recordings with the sensor tip a further $50 \mu \mathrm{m}$ away from the stalk (Fig. 5B, black arrow) detected slightly higher fluid velocities prior to contraction and a much more rapid decrease with lower minimum velocities after contraction. The fluid velocity $50 \mu \mathrm{m}$ above the basis of Vorticella sp. increased briefly after contraction and thereafter decreased only slightly below the initial value (Fig. 5A, light gray curve).

Contraction of the colonial Zoothamnium niveum caused a brief but large increase of the fluid velocity, a clear decrease that was initially rapid and then gradually slowed, interrupted by 2 small intermediate peaks, followed by a lengthier increase, the sensor tip being positioned at half the height and $400 \mu \mathrm{m}$ away from the colony (Fig. 6, black curve). The first intermediate peak occurred during the initial phase of the extension, when the proximal, contractile end of the stalk started to extend, lifting the mass of zooids and the surrounding seawater (Fig. 4A-2). The second peak corre-

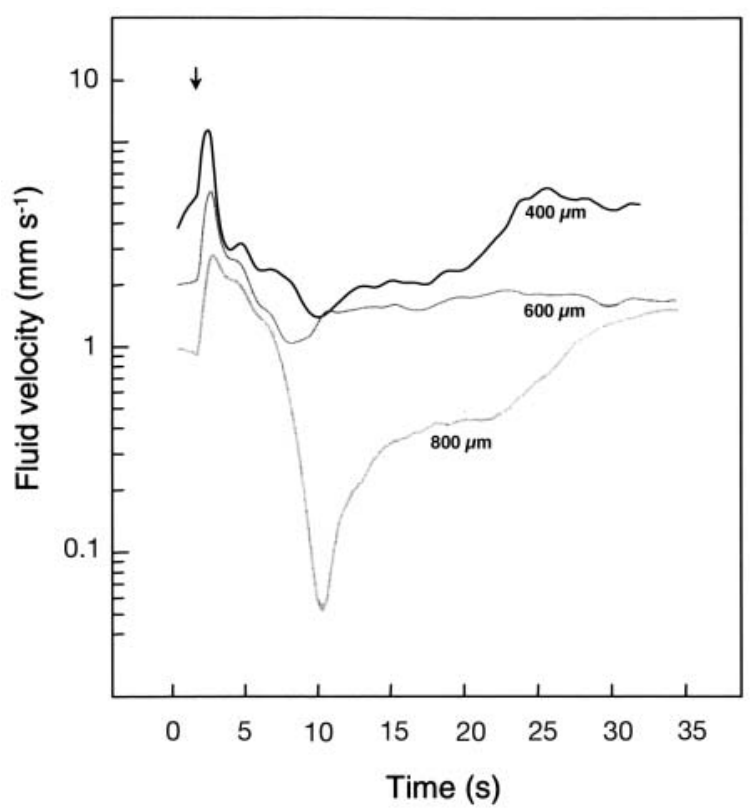

Fig. 6. Zoothamnium niveum. Continuous recordings of the seawater velocity during a full contraction/expansion cycle with a horizontal distance of the sensor tip from the colony of 400 (black), 600 (gray) and $800 \mu \mathrm{m}$ (light gray). The arrow indicates onset of contraction. The measurements were carried out successively with increasing distance of the flowsensor tip from the colony

sponded to the slow erection of the expanding feather (Fig. 4A-3). The duration of the latter movement depends on the size of the colony (Fig. 4B). Measurements with larger horizontal distances (600 and 800 $\mu \mathrm{m})$ of the sensor tip from the colony showed principally the same pattern with a more pronounced drop of the fluid velocity after contraction (Fig. 6, dark and light gray curves). The rapid contraction of the feather-shaped colonies clearly altered the flow regime close to the point of attachment (surface of substrate). This alteration is shown in Fig. 7 , which illustrates successive recordings around a $1.8 \mathrm{~mm}$ tall colony with the sensor tip positioned at increasing distances from the distal end of the stalk's non-contractile, proximal part. A brief but rapid increase of the seawater velocity was demonstrated up to a horizontal distance of at least $0.6 \mathrm{~mm}$.

\section{DISCUSSION}

The species Vorticella sp. and Zoothamnium niveum control their surroundings by continuously moving seawater and therein solutes and suspended particles. They do so in 2 ways: ciliary beat and stalk contraction. Our recordings detected maximum flow velocities 


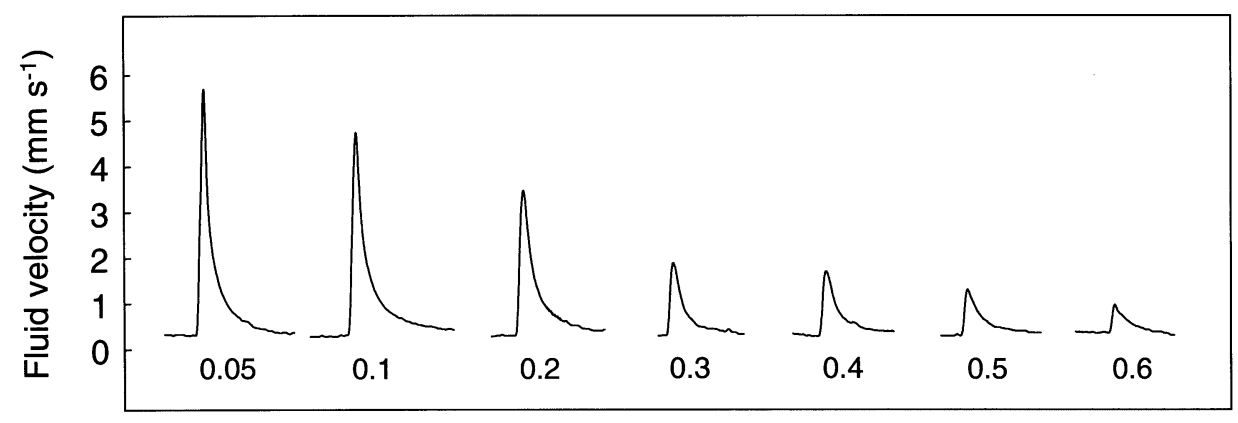

Fig. 7. Zoothamnium niveum. Fluid velocity in the vicinity of a $1.8 \mathrm{~mm}$ tall, contracting colony recorded with a horizontal distance of the sensor tip from the distal end of the non-contractile proximal part of the stalk of $0.05,0.1,0.2,0.3,0.4,0.5 \mathrm{and} 0.6 \mathrm{~mm}$. The measurements were carried out successively with the sensor positioned perpendicular to the substrate

( $18 \mathrm{~mm} \mathrm{~s}^{-1}$ close to the ciliature) that are much greater than the values published for Vorticella spp. by Sleigh \& Barlow (1976). In their experiments, Latex particles next to the ciliary tips reached a speed of at least $2.5 \mathrm{~mm} \mathrm{~s}^{-1}$. Sleigh \& Barlow (1976) calculated that the tips of the cilia, having a length of $\sim 17 \mu \mathrm{m}$ and beating at $50 \mathrm{~Hz}$, moved at a speed of only $4 \mathrm{~mm} \mathrm{~s}^{-1}$. Because the strokes of the cilia should move the seawater at almost the velocity of the tips themselves, this speed also applies to the surrounding seawater. The higher flow velocity recorded in our study could be caused by longer cilia, a lower viscosity of the seawater at higher temperature or a higher frequency of the cilia beat. Fenchel (1986) suggested that flow velocities generated by membranelles seem invariably to be within the range of 0.5 to $1.5 \mathrm{~mm} \mathrm{~s}^{-1}$ because they are constrained by functional and structural properties of eukaryote cilia and by the physics of the mechanisms for water propulsion. These velocities, however, are less than 1/10 the values measured in our study.

The flow-velocity profiles in Fig. 1 show that the ciliary beat of Vorticella sp. accelerates the surrounding seawater up to horizontal and vertical distance from the peristomial edge of the zooid of at least $400 \mu \mathrm{m}$. This distance coincides with the results of Sleigh \& Barlow (1976). The ciliate beats its peristomial cilia in a way that puts the zooid in the center of a toroidal, circulating vortex. The whirls around Vorticella sp. apparently result from friction with the feeding current drawn from above the cell into the opening between the paroral membrane and the membranelle where the ciliary system starts (Sleigh \& Barlow 1976, Fenchel 1986). The downward current along the inside of the torus is slowed and diverted by the frictional resistance of the surface to which the ciliate is attached. Because this friction affects the efficiency of the cilia in generating the feeding current (Lighthill 1976, Fenchel 1986), the ciliate raises the zooid above the substrate at a certain distance. The specimens used in our study devel- oped a stalk 6 times the filter radius in length, which supports a general assumption of Fenchel (1986): presuming a circular filter and a flow perpendicular to the solid surface, Vorticella spp. generally grow to a length of 4 to 8 times the filter radius because this distance ensures sufficient flow for filtration. A shorter stalk hampers filtration; a longer stalk yields only a marginal increase in flow.

The zooids of Zoothamnium niveum colonies feed at a larger distance from the peat surface. Although single zooids are smaller than Vorticella sp., their joint ciliary action accelerates the surrounding seawater up to a much larger distance of at least $1.2 \mathrm{~mm}$. The flow field around $Z$. niveum is complex, as the feeding current of the colony interacts with the unsteady boundary-layer flow along the peat surface. The colonies are bent back and forth by the oscillatory seawater motion along the peat surface and therefore, the orientation of their feeding currents changes continuously. This constant change might have significant consequences for the rate of movement of seawater through the feather and thus, the feeding rate of the zooids. The unsteady boundary-layer flow, the feeding currents and contraction of the colonies (see below) apparently prevent the development of steep chemical gradients and the formation of larger bacterial mats that would otherwise cover the decaying rootlets and hence, control the flux of $\mathrm{O}_{2}$ and $\mathrm{H}_{2} \mathrm{~S}$.

The genera Vorticella and Zoothamnium exhibit contraction of an all-or-nothing type, involving shrinkage of the zooid and coiling of the stalk (for details about the underlying mechanisms see Amos 1975, Ochiai et al. 1979, Katoh \& Naitoh 1992, Katoh \& Kikuyama 1997, Moriyama et al. 1999, and literature cited therein). In $Z$. niveum, the spasmonemes of the zooids are confluent in the branches, uniting in the main stem as a single trunk with a diameter between 15 and $21 \mu \mathrm{m}$ (Bauer-Nebelsick et al. 1996a). This arrangement enables even young colonies to contract 
more than 7-times faster than the solitary Vorticella sp. (see Table 1). Weis-Fogh \& Amos (1972) found that the species $Z$. geniculatum contracted at a lower speed of $280 \mathrm{~mm} \mathrm{~s}^{-1}$. The mass of zooids in the latter species is cup-shaped in fully extended, upright position, rather than feather-shaped, which may result in higher drag and thus, lower velocity during contraction. The differences between the duration of the extension of young and old colonies (Fig. 4B) are due to the differences in the feather length and the surface area exposed during the upward movement. Young colonies expose smaller surface area and therefore, complete the extension in a shorter time.

Rapid stalk contraction has been used to explain how ciliates supply their ectobiotic bacteria with $\mathrm{O}_{2}$ and $\mathrm{H}_{2} \mathrm{~S}$ (see 'Introduction'). The suggestion that this movement prevents seawater from being dragged along holds for Vorticella sp. but not for Zoothamnium niveum. The contraction of Vorticella sp. increased the velocity of the seawater $50 \mu \mathrm{m}$ above the surface only slightly, from 0.2 to $0.5 \mathrm{~mm} \mathrm{~s}^{-1}$ (Fig. 5A), indicating that little seawater is dragged along towards the surface to which the ciliates are attached. Although performed at a higher speed, the contraction of $Z$. niveum resulted in a much more pronounced increase in the velocity of the seawater both surrounding the colony and above the surface to which the colonies are attached (see Figs. 6 \& 7). Z. niveum exposes a higher surface area during contraction than Vorticella sp. and thus, generates pressure waves that push the bottom water away. In contrast, the upward movement of the zooids during uncoiling of the stalk is performed at a low velocity of $5 \mathrm{~mm} \mathrm{~s}^{-1}$ (Vorticella sp.) and 50 to $70 \mathrm{~mm} \mathrm{~s}^{-1}$ (Z. niveum). At a low Reynolds number of $3.7 \times 10^{-3}$ for the upward-moving zooid of Vorticella sp., velocity gradients are wide and gentle, so the zooids should transport a large volume of fluid (Purcell 1977, Vogel 1996). Interpretation of the flow-velocity curves recorded around Vorticella sp. (Fig. 5A, black curve) and $Z$. niveum (Fig. 6) after completion of contraction requires an understanding of the principle by which the flow sensor functions. Because the flow sensor detects a cessation of current as an increase in $\left[\mathrm{H}_{2}\right]$ at the sensor tip and because this increase depends on diffusion of $\mathrm{H}_{2}$ through the membrane of the sensor, an instantaneous cessation of actual current results in a gradual change in the signal. For example, the feeding current of the ciliates is maintained at a low Reynolds number and therefore, the fluid movement should immediately halt when cell shrinkage and stalk contraction cuts off the energy supply (Vogel 1996). The recorded signal, however, changes gradually during the following seconds (Figs. 5A \& 6) as the diffusion sphere is restored under 0 -flow conditions. Accordingly, the slopes of the curves in Figs. 5A \& 6 simply reflect the rate at which the diffusive $\mathrm{H}_{2}$ sphere around the sensor tip enlarges after the onset of contraction (i.e. cessation of flow). The sharp decrease in slope (Fig. 5A) and the 2 intermediate peaks (Fig. 6) should therefore be interpreted as a gradual or rapid-but-brief increase of flow velocity, respectively, indicating that seawater is transported upwards. The change in the slope of the flowvelocity curves recorded around Vorticella sp. (Fig. 5A, black curve) occurred 2 to $3 \mathrm{~s}$ after the start of contraction, while the zooid was still $\sim 100 \mu \mathrm{m}$ from the $50 \mu \mathrm{m}$ diffusional sphere surrounding the sensor tip. Therefore, the cell apparently forces water around it at a distance of $\sim 100 \mu \mathrm{m}$ (more than the cell diameter). This inference is also supported by the measurements illustrated in Fig. 6, i.e. the extending colony of $Z$. niveum affected the formation of the $\mathrm{H}_{2}$ sphere around the sensor tip (black curve). Here, the upward transport of seawater is caused by the unfolding and lifting of the bunched zooids, as illustrated in Fig. 4A-2, -3.

Our results support a previous study of $\left[\mathrm{H}_{2} \mathrm{~S}\right]$ and $\left[\mathrm{O}_{2}\right]$ near specimens of Vorticella sp. and Zoothamnium niveum reared on artificial $\mathrm{H}_{2} \mathrm{~S}$-releasing substrates (Vopel et al. 2001). These measurements revealed that sulphidic bottom water around the proximal region of $Z$. niveum colonies was displaced by oxygenated seawater from above after stalk contraction. In contrast, there was no increase in $\left[\mathrm{O}_{2}\right]$ due to the contraction of Vorticella sp. and thus, no oxygenated seawater was transported downwards. The recordings also detected an upward transport of deoxygenated seawater during the extension of Vorticella sp. and Z. niveum. Although in both species stalk contraction, which most likely serves to clean the oral ciliature of the zooids of larger particles, leads to a significant transport of seawater, it apparently plays only a minor role for the supply of the ectobiotic bacteria with $\mathrm{O}_{2}$ and $\mathrm{H}_{2} \mathrm{~S}$. This behavior might be important for the feeding of ciliates on their ectobiotic bacteria. Fenchel (1986) showed that in Vorticella elongata, the water that is strained for particles is drawn only from above the cell into the opening between the paroral membrane and the membranelle. Assuming that this arrangement applies also to Vorticella sp. and Z. niveum and that both species indeed feed primarily on bacteria from their ectobiotic coats, the ectobiotic bacteria must somehow become suspended in the seawater surrounding the cells and subsequently transported to regions above the cells to enter the feeding currents. Detachment of the bacteria is most likely during contraction because of the shear stress caused by the high fluid velocity around the zooids and the rapid movement of the cells. Moreover, the shrinkage of the cell during contraction (Fig. 3) decreases the area of the surface to which the bacteria are attached so that they can be expected to exert forces upon one another 
that result in detachment. Detachment of the bacteria is also supported by SEM micrographs that revealed in both species that many cells in the irregular bacterial sheaths are not directly connected to the cell wall of the ciliates (Fig. 1B in Bauer-Nebelsick et al. 1996b). That the forces on the zooids significantly increase during contraction can also be seen by considering the following: If one assumes a spherical shape for Vorticella sp., $\eta=0.9318 \mathrm{~g} \mathrm{~m}^{-1} \mathrm{~s}^{-1}$ at $26^{\circ} \mathrm{C}$ and $34 \%, r=35 \times$ $10^{-6} \mathrm{~m}$ and $V=7.1 \times 10^{-2} \mathrm{~m} \mathrm{~s}^{-1}$ (Table 1), the drag during contraction of $4.4 \times 10^{-8} \mathrm{~N}$ is $\sim 1000$ times higher than during extension $\left(3.1 \times 10^{-11} \mathrm{~N}\right)$. Moriyama et al. (1998) showed that in Vorticella convallaria the contraction velocity was not constant but increased during the first $2.8 \mathrm{~ms}$, briefly peaking and thereafter decreasing again. Because our calculation uses the mean value of the contraction velocity, it underestimates the actual maximal drag. Moriyama et al. (1998) also showed that in $V$. convallaria, the rotational forces of the helical contraction are not only counterbalanced by elasticity of the stalk but also within the zooids. This rotational force causes a twist in the zooid 3 to $5 \mathrm{~ms}$ after onset of contraction. The twist unwinds the zooid by 3 clockwise rotations that continue even after the contraction of the stalk has been completed. This movement further adds to the shear stress on the outer surface of the ciliates and therefore, increases the likelihood of detachment of bacteria. In colonies of $Z$. niveum, the zooids are bunched during folding of the stalk and consequently affect each other directly and in larger colonies, the bunched zooids strike against the surface, which further increases the mechanical stress. Once suspended, in principle, the bacteria could enter the feeding current of the ciliates.

Acknowledgements. This study was financially supported by the Austrian Science Foundation and the Caribbean Coral Reef Ecosystems program of the Smithsonian National Museum of Natural History (Washington, DC). We thank Klaus Rützler, Mike Carpenter and Dan Miller for supporting our work at Carrie Bow Cay. We are indebted to Carol Foster for the use of the video equipment. The manuscript benefited from the comments of David Thistle, Keith Suderman, Hans Roy and 3 referees. This is contribution 616, Caribbean Coral Reef Ecosystems Program, Smithsonian Institution.

\section{LITERATURE CITED}

Amos WB (1972) Structure and coiling of the stalk in the peritrich ciliates Vorticella and Carchesium. J Cell Sci 10: 95-122

Amos WB (1975) Contraction and calcium binding in the Vorticellid ciliates. In: Inoue S, Stephens RE (eds) Molecules and Cell Movement. Raven Press, New York, p 411-436

Amos WB, Routledge LM, Weis-Fogh T, Yew F (1976) The

Editorial responsibility: Fereidoun Rassoulzadegan,

Villefranche-sur-Mer, France spasmoneme and calcium-dependent contraction in connection with specific calcium binding proteins. Symp Soc Exp Biol 30:273-301

Bauer-Nebelsick M, Bardele CF, Ott JA (1996a) Redescription of Zoothamnium niveum (Hemprich \& Ehrenberg, 1831) Ehrenberg, 1838 (Oligohymenophora, Peritrichida), a ciliate with ectosymbiotic, chemoautotrophic bacteria. Eur J Protistol 32:18-30

Bauer-Nebelsick M, Bardele CF, Ott JA (1996b) Electron microscopic studies of Zoothamnium niveum (Hemprich \& Ehrenberg, 1831) Ehrenberg 1838 (Oligohymenophora, Peritrichida), a ciliate with ectosymbiotic, chemoautotrophic bacteria. Europ J Protistol 32:202-215

Fenchel T (1980) Suspension feeding in ciliated protozoa: feeding rates and their ecological significance. Microb Ecol 6:13-25

Fenchel T (1986) Protozoan filter feeding. Prog Protistol 1: 65-113

Fenchel T, Blackburn N (1999) Motile chemosensory behaviour of phagotrophic protists: mechanisms for and efficiency in congregating at food patches. Protist 150: 325-336

Hoffmann-Berling H (1958) Der Mechanismus eines neuen, von der Muskelkontraktion verschiedenen Kontraktionszyklus. Biochim Biophys Acta 27:247-255

Katoh K, Kikuyama M (1997) An all-or-nothing rise in cytosolic $\left[\mathrm{Ca}^{2+}\right]$ in Vorticella sp. J Exp Biol 200:35-40

Katoh K, Naitoh Y (1992) A mechanosensory mechanism for evoking cellular contraction in Vorticella. J Exp Biol 168: 253-267

Katoh K, Naitoh Y (1994) Control of cellular contraction by calcium in Vorticella. J Exp Biol 189:163-177

Lighthill J (1976) Flagellar hydrodynamics. Society for Industrial and Applied Mathematics (SIAM) Rev 18:161-230

Moriyama Y, Hiyama S, Asai H (1998) High-speed video cinematographic demonstration of stalk and zooid contraction of Vorticella convallaria. Biophys J 74:487-491

Moriyama Y, Okamoto H, Asai H (1999) Rubber-like elasticity and volume changes in the isolated spasmoneme of giant Zoothamnium sp. under $\mathrm{Ca}^{2+}$-induced contraction. Biophys J 76:993-1000

Ochiai T, Asai H, Fukui K (1979) Hysteresis of contractionextension cycle of glycerinated Vorticella. J Protozool 26: $420-425$

Ott JA, Bright M, Schiemer F (1998) The ecology of a novel symbiosis between a marine peritrich ciliate and chemoautotrophic bacteria. PSZN I: Mar Ecol 19:229-243

Purcell EM (1977) Life at low Reynolds number. Am J Phys 45: $3-11$

Rützler K, Macintyre IG (1982) The habitat distribution and community structure of the barrier reef complex at Carrie Bow Cay, Belize. In: Rützler K, Macintyre IG (eds) The Atlantic barrier reef ecosystem at Carrie Bow Cay, Belize, Vol I. Structure and communities. Smithsonian Institution Press, Washington, p 9-45

Sleigh MA, Barlow DI (1976) Collection of food by Vorticella. Trans Am Microsc Soc 95:482-486

Vogel S (1996) Life in moving fluids. Princeton University Press, Princeton, NJ

Vopel K, Pöhn M, Sorgo A, Ott J (2001) Ciliate-generated advective seawater transport supplies chemoautotrophic ectosymbionts. Mar Ecol Prog Ser 210:93-99

Weis-Fogh T, Amos WB (1972) Evidence for a new mechanism of cell motility. Nature 236:301-304

Submitted: December 21, 2001 Accepted: April 18, 2002

Proofs received from author(s): July 29, 2002 